\title{
CRITICAL DATA: TEACHING DESIGN THROUGH CRITICAL DESIGN, PHYSICAL COMPUTING, AND DIGITAL DATA
}

\author{
José Rodrigo DE LA O CAMPOS and David GÜEMES-CASTORENA \\ Monterrey Institute of Technology and Higher Education, Mexico City, México
}

\begin{abstract}
Industrial design students in Mexico carry educational backwardness that does not allow them to learn new skills related to problem-solving, critical thinking and technology. Especially if industrial design has had to acknowledge that products will have to respond to the demands brought by the Internet of Things. Mexico is a struggling country in terms of design and innovation as it has been in the bottom of most indicators used by the OECD to measure science, technology, and innovation in the last ten years, obtaining the $56^{\text {th }}$ position on the Global Innovation Index. We foresee that Mexican companies would need to recruit talent that could implement innovation and technology on a faster pace with a deep understanding of the limitations of its context and a problem-solving attitude toward new challenges. We describe how, by using critical design and challenge-based learning, we could incentivise students to develop skills related to critical thinking, problem solving and technology. A case study is described with its methodologies and tools on implementing critical design on challenge-based-learning methods. Through a survey, we learned that after each exercise, most of the students perceived that they felt more confident using and understanding technology, as well as having a better understanding of their context, learning new methodologies and felt more prepared to face their professional life. By sharing our methodologies and results through this article, we hope to encourage other scholars, design educators and designers to use critical design as a tool for education in an ever-changing context.
\end{abstract}

Keywords: Industrial design, critical design, challenge-based education, critical thinking, educational innovation

\section{INTRODUCTION}

Mexico is a country that still has a lot to do in terms of design and innovation. Mexico finds itself at the bottom of the indicators by the OECD as a country able to innovate and develop new technology on both the public and private sectors [1]. One of the main reasons Mexico has a lack of innovation are the levels of research and development, (R\&D) are considerably low, as Mexican firms are the one among the OECD that invest the least in R\&D [2]. If design is a discipline that relies on $\mathrm{R} \& \mathrm{D}$, one could conclude that Mexico lacks design development [3].

Besides, Mexico suffers from low digitalisation. Even if half of the population in Mexico could have access to the internet, in infrastructure, Mexico has the worst OECD ranking in wireless broadband penetration with only $14 \%$ of its population with access to this technology and one of the lowest proportions of the OECD on Mexican business with broadband internet connection with only a 52\%. With a very poor digitalisation, Mexican companies would need to increase innovation through hyperconnected products and services like e-commerce, digital assistants or services based on mobile platforms faster than its international counterparts [3], [4]. This is why these firms would need talent that could implement innovation and technology on a fast pace understanding the limitations of its context and having a problem-solving attitude toward new challenges. So, this brings the question: Are students ready and prepared to face these challenges? The immediate answer is no. As the lack of human capital development contributes not only to the lack of innovation, but the potential growth of GDP [5]. 


\section{CHALLENGES IN HIGHER EDUCATION FOR INDUSTRIAL DESIGNERS IN MEXICO}

If we continue to review Mexico under the lens of the OECD, we can find that the ranking in education has areas of opportunity. Even though enrolment on tertiary education has been growing steadily since 2000, it remains below the OECD average of 44\% [6]. According to Nicolín, Mexico suffers from several constant problems in education: lack of coverage, inadequate management, insufficient resources, and quality. As students move from primary, to secondary to tertiary education, the quality of education can turn into a performance problem, as secondary education certificates can be valid to demand admission to the university but does not necessarily back the learning quality [7]. Lack of quality in education can be found through primary school, where, according to Davis, the governmentmandated curriculum based on lectures, memorisation, and busy work could feel "mind-numbingly boring" as students could get good grades without overthinking [8]. Primary education in Mexico can be seen as a preparation for a workspace rooted in the industrial revolution, where punctuality, regularity, and attention, are still valued. How are students going to generate new skills if they carry these educational deficiencies?

\subsection{Active learning and critical thinking}

Recently, LinkedIn, announced that skills companies are looking the most: creativity, persuasion, collaboration and adaptability [9]. If undergraduates carry a way of learning closer to what it was seen as good skills 40 years ago, the panorama for these students is pretty alarming.

We see the necessity of generating educational projects that could tackle all the described deficiencies in a very rapid way. However, where to start? Scholars suggest using the four pillars of education of Delors, that engages learning through by learning to know, the ability to learn throughout life, learning to do, the ability to learn to deal with many situations through teamwork, learning to live together as in developing empathy and conflict resolution and lastly, learning to be (to develop one's personality and be able to act with greater autonomy) [10].

One way to start implementing these pillars into education is to encourage students to think for themselves. Pitchers \& Soden describe "good thinking" as the ability to identify questions worth pursuing, being able to pursue one's questions through self-directed search and interrogation of knowledge, a sense that knowledge is contestable and being able to present evidence to support one's arguments. Pitchers \& Soden identify several similarities between "good thinking" and the term "critical thinking" used on a body of research to describe reasonable, reflective thinking, focusing on the task, people or belief [11]. The importance of implementing critical thinking in design education lies on the understanding that critical thinking helps to cope with problems with fundamental differences, like the ones may face on the technical domain and the "logically messy-real world problems" [12].

We see that one of the tactics to promote critical thinking on students is through challenge-based learning, where the students, on a collaborative way, must solve a problem through the phases: challenge, generation of ideas, a contribution of visions, research, skill test and publication of the solution. Challenge Based Learning (CBL) is inspired by the search for solutions to significant global challenges and originated in context external to one's field of work. [13]. We find many similarities on the phases of CBL and design methods, as both methodologies require discovering insights related to a problem, validating ideas and designing or "publishing" a solution. It comes naturally to implement tactics related to CBL on an academic design project as the student may be used to problem-solving behaviour, but, is there any discipline in the design field that could we use to enhance critical thinking?

\section{CRITICAL DESIGN AS A TOOL TO ENHANCE EDUCATION FOR INDUSTRIAL DESIGNERS}

Critical design is a design approach that critiques current social, cultural, technical, and economic controversies and hegemony through designing critical artefacts that could engage user audiences in the discussion [14]. In the early nineties, Anthony Dunne and Fiona Raby developed an approach to generate conceptual electronic products that encourage complex and meaningful reflections on technology and how it is influencing one's everyday life. This critical approach on a culture of "relentless innovation for its own sake" utilises tools usually related to the traditional practice of design in order to generate these conceptual products [15]. In their book, Speculative Everything, Dunne \& Raby offer a plethora of examples and case studies on how design has tried to challenge different aspects of society by 
separating themselves from the marketplace in order to explore new ideas that could be restrained by a more traditional commercial-based, user-centred design approach [16].

\subsection{The Dangers of Critical Design}

As we find critical design as an approach exciting and fun, one should approach critical design with caution. Perhaps one of the main dangers is the ambiguity on how to measure the success of a critical design product. As critical design is closely attached with future thinking and speculation, these "conceptual products" are designed for hypothetical users from a parallel reality or a future scenario. As Dunne \& Raby conveniently argue that the exhibition space is the main platform to present the result of research and experimentation it would be tough to measure the success of a "product" solely on how much provocation it generates.

A second problem could be the amount of fiction a critical design project would carry. As critical design relies on narrative, if the story around the concept of the critical product, turns to be a way too strange or fantastic, the audience might dismiss or reject the concept. The same thing can happen to the outcome. A "Critical Product" has to achieve a sort of "slight strangeness" that some researchers can find difficult to achieve as "it plays out across conceptual, functional, material, and aesthetic dimension of design in complex ways" [17].

A third potential problem is vagueness of approach. Even if Dunne \& Raby literature and work can be inspiring, they offer little clarity on how to implement critical design. Barzdell \& Barzdell strongly criticise how Dunne \& Raby depict this practice by evidencing a lack of methodology:

"Dunne \& Raby offer few specifics on how this is done, and they characterise critical design as more of an "attitude" than a "method." Indeed, we could find minimal methodological direction anywhere in their writings, though they imply one on their use of words like "transgression, "provocation," "satire," and the "standing of dilemmas" [18].

In conclusion, we find critical design not as a tool to be deployed on the "real world" but as a learning process for design students to engage in critical thinking while designing through CBL.

As Dunne \& Raby points out: "We are more interested in critical thinking, that is, not taking things for granted, being sceptical, and always questioning what is given. All good design is critical. Designers start by identifying shortcomings in the thing they are redesigning and offer a better version. Critical design applies this to larger more complex issues." [16].

As designers can find themselves engaged with CBL because of the nature of the design education (at least once a semester, a design student has to design a specific product following a brief and get an evaluation from that), we believe that critical design can provide an extra incentive to encourage students to develop critical thinking. For this to happen, it is imperative that the design educator fully understand the context, the challenges and the limitations of the problem that the design project would be generated around.

\section{CASE STUdies}

In this section, we will describe an academic project that aim to motivate the students to engage with the Internet of Things, physical computing and critical thinking. We presented the following challenge to the students: "To design a physical product that will be able to connect to a network, and capture, process and interpret information in such a way, that could generate a critique of a problem raised from the transversal axes established by the Design World Capital Organisation for Mexico City. The device may obtain data from other external databases or collect data in some other specific way. The user will be able to interact with the object physically and virtually. It will not be possible to manage only digital interfaces. The Artefact will generate criticism either through the functional aspect, its physical aspect or its interactive aspect".

As this project was data-centric, it was decided that the artefact could connect or download data generated by an open entity (Waze, Google News or the Weather Channel for example) but also it would be considered as data gathering if this artefact could capture data through a physical interface by the user, like buttons, levers or other physical devices. One of the main objectives focused on challenging the student to translate their critique into three aspects of the artefact: its functionality, how it would look physically or how a user would interact with it. As each team was developing their concepts, they had to tackle the technical aspect of the project at the same time. By learning by doing, some of our students had to find technical solutions on physical computing, data mining, and robotics; it is worth mentioning that most of the students did not have any previous experience in these activities. The class 
consisted of seven teams of students, from three to four members where each tackled a specific problem, from mobility, nutrition, gender equality among others, generated a concept and designed their artefact. In this paper, only two projects will be described as follows.

\subsection{Case 1: Parallel Mexico}

México Paralelo translates from Spanish as Parallel Mexico. So as its name suggests, describes parallel realities of Mexico City. After some weeks of research, this team of students asked themselves what would Mexico City be like if the decisions on infrastructure had been different?

Throughout their research, the students found that one of the critical decisions in the city was to pipe the rivers running through the city. In the early 1950s, Mexico City suffered a flood that registered an increase of 12 centimetres per hour. This flood, in addition to other health and drainage problems, led to the decision to pipe several rivers and canals becoming one of the main streets and avenues of the city. The students believe that this has not been the best solution and they think that if at that moment they had had better strategies, Mexico City would have a better quality of life. On one side, having collected information from other cities where water bodies were conserved, the students concluded that knowing how to take advantage of rivers in a city can improve aspects such as a more comfortable temperature, less traffic, more water per capita and lower $\mathrm{CO}_{2}$ emissions. On the other side, researching data on mega-urban areas in Asia and Africa where there is a more significant lack of water, could observe that these same factors, such as $\mathrm{CO}_{2}$, temperature, and traffic increased considerably.

As a consequence, students began to speculate three parallel scenarios comparing the three factors influenced by the amount of water: temperature, $\mathrm{CO}_{2}$ and traffic. To communicate the variants between each scenario, they designed an artefact that plotted each variable in real time. The artefact resulted in a mixture between a clock and seismograph, draws the progress of three different variables throughout the day: temperature, traffic and $\mathrm{CO}_{2}$ emissions. The "face" of the artefact rotated at a speed of one revolution per day, where the viewer can compare in real time the three possible cities. By translating their research into a designed artefact driven by quantitative data, México Paralelo questions how many of the decisions in our city do not consider the possible long-term consequences.
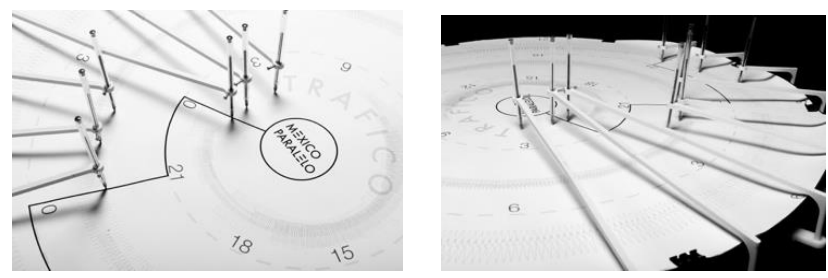

Figure 1. Parallel Mexico

\subsection{Case 2: Fear}

The second project discusses gender problems that occur in Mexico City. This project named simply "Miedo" (Spanish for fear), started with the finding that in just three years, complaints of sexual harassment have increased $433 \%$ in Mexico City, being the most registered in public places where they occur the most. Consequently, this team observed that in Mexican popular culture, society perceives highly sexual female actresses appear during morning television as something normal. The team believed that the contribution to the normalisation of sexual harassment by the media resulted by promoting a stereotype of the Mexican Macho, which is considered superior to the female gender, where the way of interacting is with a strange mixture between paternalism and arrogance (perhaps as a reflection of the impotence suffered by being a member of an oppressed class the team found out), but at the same time it is accepted to be childish, irresponsible and primitive. Taking this contribution to popular culture as a central criticism, this team decided to demystify this stereotype by designing a way to express the fear a woman might feel when interacting with one of these Machos. After analysing several scenes of films considered as "golden classics of the Mexican cinema," the team observed the behaviour of characters played by legendary Mexican actors like Pedro Infante, Jorge Negrete or Pedro Armendariz while interacting with women and measured when these interactions to the point where they were considered sexual harassment. The result was an artefact that uses an analogy of the sensation of fear and anxiety that is experienced when a woman is harassed in public spaces rising in response to the scenes according to the intensity of the same. Housed in a glass cap, the team designed a mechanism that makes iron fillings move and spike through moving magnets as it reads the dialogue of a specific scene from a 
classic movie. By "looking" at the scenes on a neighbouring small screen, this artefact will gradually "bristle" as the scene turns violent towards women, generating a provocative empathy to the viewer.

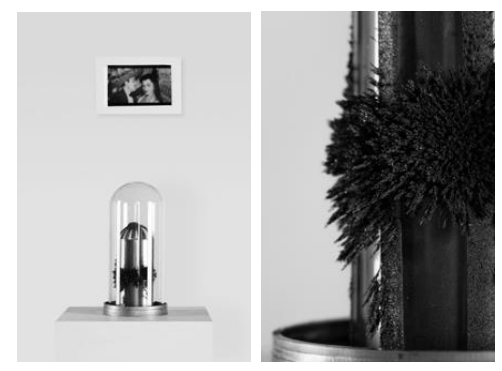

Figure 2. Fear

\subsection{Breakdown}

One of the main challenges students faced during this particular exercise were understanding the conceptual part of the project and the challenge of learning physical computing and data. As we discussed before, students are used to, even in tertiary levels, to follow the educator without questioning. For some, it was frustrating to "learn by making," finding relevant literature or to figure out technical aspects of the challenge without an instructor to solve their issues for them. Before this class, students were used to working on a more linear fashion, away from a position of uncertainty or ambiguity. For them, it was frustrating to have their weak concepts rejected, to repeat tasks like prototyping and to push further into quantitative research. Also, it was a bit difficult for them to separate fact from anecdotal information. Nevertheless, we believe the results for these projects where outstanding. These projects were invited to an exhibition part of Design Week Mexico representing the Monterrey Institute of Technology. The project Parallel Mexico was awarded an honour of "best concept of the show."

\section{SURVEY}

A survey was realised to try to measure the impact these exercises had on the students. Twenty one students were participating in two critical design projects, including the ones from the projects above. The survey was composed of 24 multiple choice questions ranging from if they feel more comfortable with using and applying technology and their perception problem-solving skills and critical thinking. The majority of the group agreed that even if they never had any experience with physical computing, digital data or coding, after this type of academic exercises, they had the perception of a better understanding of technology. Also, the majority of the students agreed on using new learning methodologies that they had never used before, developed a better understanding on their context, strengthened the importance of finding a different point of views while finding a design concept. More than half of the students strongly agreed or somewhat agreed that after this course, developed a more critical opinion on their context. Finally, the majority of the students have the perception that after this project, feel more prepared to face their professional life.

\section{CONCLUSIONS}

Even if the results of the survey can be taken as optimistic, it is difficult to truly measure if these group of students truly learned these skills. Also, learning a new skill takes time and practice where it would be too favourable to think that these students will radically change the way they think and become experts in dealing with technology. Nevertheless, we strongly suggest that these academic practices are at a high starting point.

What we could learn for future exercises while deploying these types of practices on industrial design students, the educator has to keep in mind that the student would be displeased and frustrated on situations of uncertainty and act accordingly to minimise these feelings, perhaps by warning the student about this frustration. Another aspect to keep in mind would be to measure the technical challenge and provide some learning tactics and practices related to physical computing through external advisors, literature or online platforms. Lastly, we suggest the educator be ready to deal with potential conflicts between students as some would not be performing evenly, feel frustrated or demotivated.

However, even with these potential challenges, we had found that the result of these two projects had transcended the teaching room and had outstanding recognition outside academia. We like to share these 
experiences with the design and engineering community hoping to encourage other scholars and educators into diving deeper into the potential of critical design as a tool for education in an everchanging context. The authors would like to acknowledge the financial and the technical support of Writing Lab, TecLabs, Tecnologico de Monterrey, Mexico, in the production of this work.

\section{REFERENCES}

[1] Riquelme R. (2018, September 19). México reprueba en innovación y desarrollo dentro de la OCDE, El Economista. Retrieved from https://www.eleconomista.com.mx/tecnologia/Mexicoreprueba-en-innovacion-y-desarrollo-dentro-de-la-OCDE-20180918-0089.html

[2] OECD Secretary-General (2018, March 12). Competitive Mexico: Challenges and Opportunities. Retrieved from http://www.oecd.org/economy/competitive-mexico-challenges-and-opportunitiesmexico-march-2018.htm

[3] OECD Competition Division (2018, June 6) Implications of E-commerce for Competition Policy. Retrieved from http://www.oecd.org/daf/competition/e-commerce-implications-for-competitionpolicy.htm

[4] Montiel J.M. (2016). The Digital Divide in Mexico: A Mirror of Poverty. Mexican Law Review,9(1), 93-102. doi:10.1016/j.mexlaw.2016.09.005

[5] Guichard S. (2005), "The Education Challenge in Mexico: Delivering Good Quality Education to All", OECD Economics Department Working Papers, No. 447, OECD Publishing, Paris, https://doi.org/10.1787/047122723082.

[6] OECD. (2019, Jan 10). Chapter 2. Key features of higher education in Mexico. Retrieved from https://www.oecd-ilibrary.org/sites/9789264309371-5en/index.html?itemId=/content/component/9789264309371-5-en

[7] de Ibarrola Nicolín M. (2012). Los grandes problemas del sistema educativo mexicano. Perfiles educativos, 34. Retrieved from http://www.scielo.org.mx/scielo.php?script=sci_arttext\&pid=S0185-26982012000500003

[8] Davis J. (2013, October 15). A Radical Way of Unleashing a Generation of Geniuses, Wired, 21(11). Retrieved from https://www.wired.com/2013/10/free-thinkers/

[9] Petrone P. (2019, January 1). The Skills Companies Need Most in 2019 - And How to Learn Them. Retrieved from https://learning.linkedin.com/blog/top-skills/the-skills-companies-needmost-in-2019--and-how-to-learn-them

[10] Zuñiga Sanches M. (2012). Los estudiantes universitarios del siglo XXI en méxico: de los estudiantes universitarios del siglo XXI en méxico: de la pasividad a la autonomía y al pensamiento crítico, Teoría de la Educación. Educación y Cultura en la Sociedad de la Información, 13 (2). Retrieved from http://www.cite2011.com/Comunicaciones/Escuela/166.pdf

[11] Pithers R. and Soden R. (2000). Critical thinking in education: A review. Educational Research,42(3), 237-249. doi:10.1080/001318800440579

[12] Paul R.W. (1983, November 30). Critical Thinking: Fundamental to Education for a Free Society, Educational Leadership, 42 (1). Retrieved from https://eric.ed.gov/?id=EJ306669

[13] Fidalgo Blanco Á., Sein-Echaluce Lacleta M.L. and García Peñalvo F.J. (2017). Aprendizaje Basado en Retos en una asignatura académica universitaria. Revista Iberoamericana De Informática Educativa,25(Enero-Junio), 1-8.

[14] Malpass M. (2017). Critical design in context: History, theory, and practices. New York: Bloomsbury Academic.

[15] Dunne A. (2008). Hertzian tales: Electronic products, aesthetic experience, and critical design. Cambridge, MA: MIT.

[16] Dunne A. and Raby F. (2014). Speculative Everything: Design, fiction, and social dreaming. S.l.: MIT.

[17] Bardzell S., Bardzell J., Forlizzi J., Zimmerman J. and Antantis J. (2012). The challenge of designing for provocation. Retrieved from https://dl.acm.org/citation.cfm?id=2318001

[18] Bardzell J. and Bardzell S. (2013). What is critical about critical design? Retrieved from https://dl.acm.org/citation.cfm?id=2466451 